EPiC Series in Language and Linguistics
Volume 2, 2017, Pages 224-234
Professional and Academic Discourse:
an Interdisciplinary Perspective

\title{
Semiotic Modes in the Organization of Lectures in English and in Spanish
}

\author{
Edgar Bernad-Mechó and Inmaculada Fortanet-Gómez \\ Universitat Jaume I, Castelló de la Plana, Spain \\ ebernad@uji.es, fortanet@uji.es
}

\begin{abstract}
This paper aims at describing from a multimodal discourse analysis perspective, the organizational metadiscourse elements (and previewing and reviewing instances in particular) employed in academic lectures in English and in Spanish in order to connect speech events and structure the discourse. We believe that a multimodal approach (Fortanet-Gómez \& Ruiz-Madrid, 2014; Querol-Julián, 2010; Querol-Julián \& FortanetGómez, 2012) provides a deeper understanding of how meaning is conveyed not only through linguistic elements but also through non-verbal items like paralanguage and kinesics.

In order to carry out this study we selected two lectures in English from an African American Studies course which is part of Yale University's collection of OpenCourseWare, and two lectures in Spanish from a Human Resources Studies course recorded at Universitat Jaume I. With the aim to describe possible recurrent patterns and relationships between verbal and non-verbal (paralinguistic and kinesic) elements, we will carry out a MDA in three phases: a linguistic transcription and identification of organizational metadiscourse using Ädel's $(2006,2010)$ model and taxonomy of metadiscourse for spoken academic English; a transcription of paralinguistic features (syllabic duration and loudness) and kinesic elements (hand-arm gestures); and an analysis of co-occurrences of modes to understand how meaning is conveyed.

The final objective of this study is twofold, i) to approach multimodal academic discourse from a contrastive perspective and ii) to use the results for EAP training courses for Spanish teachers and students, as it has been observed that verbal and non-verbal discourse needs awareness raising in order to facilitate transfer from mother tongue to another language.
\end{abstract}

\section{Introduction}

This study is encompassed within spoken academic discourse analysis and multimodal discourse studies. Discourse analysis in university lectures has become more and more relevant for researchers in 
recent years (Crawford-Camiciottoli, 2007; Csomay, 2007; Deroey \& Taverniers, 2011; Pérez-Llantada \& Ferguson, 2006). Similarly, one of the most widely studied fields of language within discourse studies is metadiscourse (Vande Kopple, 2012). Metadiscourse has been studied from many different perspectives and in many distinct languages (Hyland, 2005). However, there is a clear lack of research where metadiscourse in academic lectures is examined from a multimodal point of view, taking into consideration the several semiotic modes that are used by the speaker to convey meaning. Some of the very few examples could include Querol-Julián(2011) or Querol-Julián and Fortanet-Gómez(2012), who examine how evaluation (or stance in some other approaches to metadiscourse) is expressed from a multimodal perspective, taking a look not only at the language, but also at paralinguistic and kinesic features. Multimodal discourse analyses (MDA) have proven the relevance of the presence of these semiotic systems and the relationships among them, which adds a particular communicative value to the linguistic message conveyed (Fortanet-Gómez \& Ruiz-Madrid, 2014; Querol-Julián, 2010; QuerolJulián \& Fortanet-Gómez, 2012).Therefore, the aim of this study is to take a closer look and revisit the concept of metadiscourse from a multimodal perspective in order to shed some light on how lecturers organize their lectures through the use of multimodal metadiscourse. More specifically, we set out to investigate fragments where the lecturers preview or review information, which contributes to the cohesion of the lecture as well as to link one session with the other. Metadiscourse is an essential category when it comes to organizing the discourse and accommodating the language to facilitate interaction with the audience. It is particularly so when dealing with academic genres (Hyland, 2005; Toumi, 2009).

A second aim of this paper is to contrast and compare the use of organizational metadiscourse in two different languages: Spanish and English. We intend to account for any differences and peculiarities between languages in the use of this type of metadiscourse at three levels: linguistic, paralinguistic and kinesic. In order to do so, as we will further develop in the Methodology section below, we will take a look at four lectures in Social Sciences -two in Spanish and two in English, from African American History and Human Resources Administration courses respectively-.

\section{1 Ädel's (2006, 2010) Model of Metadiscourse}

For the purposes of this paper we are determined to utilize Ädel's (2006) model of metadiscourse (the reflexive model) and Ädel's (2010) taxonomy of metadiscourse in spoken academic discourse. Ädel's model of metadiscourse suggests a narrower approach towards what can be considered as metadiscourse and what cannot. Previous models -see for instance Crismore, Markkanen, and Steffensen, (1993); Hyland and Tse, (2004); or Vande Kopple, (1985) - traditionally identify metadiscourse with all non-propositional material -following Halliday's (1973) theory on the functions of language- and include categories (like stance, for instance) which can also be interpreted as carriers of propositional content paradoxically. Consequently, Ädel advocates the use of Jakobson's (1960) theory of the six functions of language instead, in order to overcome the proposition problem as well as to further refer to the interaction between the writer and the reader while emphasizing the concept of reflexivity of language (see Ädel 2006:12). Another of the characteristics shared by most traditional models is the focus on written discourse; it was not until the end of the 1990's and beginning of the 2000's that researchers began to turn towards the study of spoken genres. In this sense, Ädel (2010) provides a comprehensive and extensive taxonomy of metadiscourse in spoken (and written) academic English. By carrying a corpus-driven investigation on 30 university lectures and 130 essays, she puts 
forward a distinction of 23 different discourse functions. Table 1 below lists these categories together with examples.

\begin{tabular}{|c|c|}
\hline Type of metadiscourse & Example \\
\hline \multicolumn{2}{|l|}{ METATEXT } \\
\hline \multicolumn{2}{|l|}{ Metalinguistic comment } \\
\hline Repairing & I'm sorry, that's not correct. \\
\hline Reformulating & Let me put it in other words... \\
\hline $\begin{array}{l}\text { Commenting on linguistic } \\
\text { form/meaning }\end{array}$ & I'm not sure how to say this, but... \\
\hline Clarifying & $\begin{array}{l}\text { Now, I'm not saying that is the case, what } 1 \\
\text { mean is that... }\end{array}$ \\
\hline Managing terminology & Let's take a look at what metadiscourse means. \\
\hline \multicolumn{2}{|l|}{ Discourse organization } \\
\hline Introducing topic & $\begin{array}{l}\text { Today I want to talk about the American } \\
\text { Revolution. }\end{array}$ \\
\hline Delimiting topic & We won't go into that in this class. \\
\hline Adding to topic & $\begin{array}{l}\text { Let me add to that that, it was not until } 1785 \\
\text { that... }\end{array}$ \\
\hline Concluding topic & $\begin{array}{l}\text { Now, we've seen how Americans became } \\
\text { independent and how... }\end{array}$ \\
\hline Marking asides & I want to do an aside here... \\
\hline Enumerating & $\begin{array}{l}\text { There are two aspects you should know about; } \\
\text { first... (...) and second... }\end{array}$ \\
\hline Endophoric marking & Please look at page 373 from your book. \\
\hline Previewing & We'll talk about that in our class next week. \\
\hline Reviewing & Last lecture I talked about... \\
\hline Contextualizing & $\begin{array}{l}\text { I believe I still have a couple of minutes to talk } \\
\text { about this. }\end{array}$ \\
\hline \multicolumn{2}{|l|}{ Speech act labels } \\
\hline Arguing & I will argue that they did not plan it like that. \\
\hline Exemplifying & Let me give you an example of that... \\
\hline Other speech act labeling & I want to remind you that... \\
\hline \multicolumn{2}{|l|}{ AUDIENCE INTERACTION } \\
\hline \multicolumn{2}{|l|}{ References to the audience } \\
\hline Managing comprehension/channel & Can you hear me back there? \\
\hline Managing audience discipline & May I have your attention, please? \\
\hline Anticipating the audience's response & You'll probably think that I am wrong... \\
\hline Managing the message & $\begin{array}{l}\text { What I want you to think about is how all these } \\
\text { elements... }\end{array}$ \\
\hline Imagining scenarios & Now, imagine you have to do that. \\
\hline
\end{tabular}

Table 1: Ädel's (2010) taxonomy of metadiscourse in academic English

The scope of this paper is the examination of how information is connected through the use of metadiscourse. Accordingly, our focus will be on the previewing and reviewing instances of metadiscourse. Previewing and Reviewing are two of the most important types of metadiscourse within the category of Discourse organization; they point to previously disclosed information within the 
discourse or to information that will be (or is about to be) revealed in the future. They may refer to the lecture itself or to previous or next lectures. We argue that these types of metadiscourse provide cohesion and contribute to a proper guidance of the students through the classes by connecting ideas from one side to the other of separate phases of lecturing.

\subsection{Multimodal Discourse Analysis (MDA)}

In order to obtain a holistic account on how organizational metadiscourse is used by lecturers to preview and review information, we suggest conducting a Multimodal Discourse Analysis (MDA). As Prior (2009:27) argues, "all genres are irremediably multimodal" and "the question then becomes what particular configurations of multimodality are at work". A MDA allows us to look beyond words at how meaning is conveyed through the combination of different semiotic modes like hand gestures or intonation, for example. This series of semiotic modes might describe possible recurrent patterns and relationships between verbal (linguistic) and non-verbal (paralinguistic and kinesic) elements. Based on previous multimodal studies on spoken academic discourse (Fortanet-Gómez \& Ruiz-Madrid, 2014, 2015; Querol-Julián, 2011; Querol-Julián \& Fortanet-Gómez, 2012), and especially on Ruiz-Madrid and Fortanet-Gómez' (2015) contrastive multimodal analysis, we decided to carry out a MDA in three phases:

- First, the desired linguistic elements (previewing and reviewing metadiscourse) are identified and isolated in the transcriptions and a linguistic analysis is conducted.

- The second phase consists in identifying and transcribing paralinguistic and kinesic elements in the selected fragments. Due to space limitations, we will focus our examination on the analysis of syllable duration and loudness (paralinguistic features), and hand-arm movements (kinesic elements). This transcription is performed in ELAN, software that allows for multimodal annotation. For more information, see the Methodology section below.

- The last step is an analysis of the co-occurrences of modes in the selected fragments and a description of how meaning is conveyed through the interaction of linguistic elements with paralinguistic and kinesic features in both, lectures in Spanish and in English.

\section{Methodology}

To carry out our analysis we selected four university lectures on Social Sciences from two different OpenCourseWares: Yale's University's official collection of courses and a course taught at Universtitat Jaume I and uploaded at humansite.net. Among all possibilities offered at Yale's OpenCourseWare we chose two lectures from a course on African American History entitled "AFAM-162 African American History: From Emancipation to the Present" and taught by Prof. Jonathan Holloway. The choice for the lectures in Spanish was much more restricted due to the lack of availability of comparable materials; we eventually decided to use material for a course taught by Prof. Antonio Grandío: "RL0929 Dirección y Gestión de Recursos Humanos II” belonging to the Degree on Labor Relations and Human Resources. It is important to remark that these are not on-line courses; they are face-to-face traditional courses. Some of the classes were recorded and then uploaded to the Virtual Sites of the courses on the Internet. The courses were meant to be face-to-face and there is no reference or adaptation for the on-line audience.

The sample in English consists of two lectures (lectures 7 and 8 out of 25) taught at Yale University in 2010 with a running time of 47 and 43 minutes respectively. We decided to choose lectures that were not too close to the introduction or the closure of the course where more previewing and reviewing fragments might be expected when introducing or summarizing the whole course. The sample of 
lectures in Spanish consists of two lectures (lectures 6 and 9 out of 12) taught at Universitat Jaume I in 2014 with a full length of 78 and 77 minutes respectively. In order to account for the difference in the time span between both samples, we resolved to calculate all quantitative analyses on the basis of 10.000 -word chunks. In both cases it was highly relevant for us to pick out lectures that had been recorded from a medium shot, i.e. from right below the waist to some centimeters above the head, so the lecturer was close enough to the camera (and not too close) and all kinesic expressions could be clearly identified. Moreover, microphones had been installed close enough to the lecturers so that sound and voice were distinctly understandable.

The first step for the analysis, as we hinted in the previous section, was to go through the linguistic transcriptions of the lectures in order to identify and classify all fragments of organizational metadiscourse. Since the size of the dataset is rather manageable, this process was carried out manually and therefore, we made sure all occurrences were located. Initially we spotted examples from all ten types of organizational metadiscourse in Ädel's (2010) taxonomy, which we will consider in terms of numbers, even though only previewing and reviewing instances would go on to the second phase.

Once organizational metadiscourse of the lectures had been identified, we conducted a multimodal transcription of all previewing and reviewing examples. In order to do this, we made use of ELAN", a tool for multimodal annotation. This software also enabled us to create different tiers where modes would then be described. We created four different tiers: transcription was used to include the linguistic transcription synchronized with the video and the audio waveform; metadiscourse would describe whether we were looking at an instance of previewing or reviewing; paralanguage was used to indicate any unusual pauses, changes in the speed at which the lecturer would speak (syllabic duration), and changes in the volume of the speaker (loudness); and finally the tier labeled gestures was used to incorporate to the multimodal analysis those hand-arm movements performed by the lecturers. Additionally, gestures were classified following Querol-Julián's (2011) model of kinesics: iconic when there is a relationship with the semantic content of speech; metaphoric if there is a relationship but the gestures present abstract ideas; beats, which are repeated throughout the discourse marking the rhythm of it; and deictic if the gesture points to something concrete or abstract.

The last stage of the analysis involved looking at both, the number of instances of organizational metadiscourse used, and the whole multimodal ensemble, with the aims of describing the use of organizational metadiscourse and explaining any multimodal co-occurrences that would shed some light on how meaning is conveyed in previewing and reviewing fragments while accounting for any differences or similarities between both languages.

\section{Results and Discussion}

\subsection{Metadiscourse in Numbers}

One of the first aspects we looked at after identifying all instances of organizational metadiscourse in both sets of lectures was the number and types of fragments. The total number of organizational metadiscourse fragments found in the lectures in English was 68, while the amount of fragments in the lectures in Spanish was 74. However, we must recall that we are dealing with lectures of different running times so, when we compare the number of instances per every 10.000 words we recognize the first thought-provoking fact: the Spanish lecturer uses 30.46 instances of organizational metadiscourse per 10.000 words while the American one uses 57.1; that is almost twice the amount of organizational metadiscourse used in Spanish. We hypothesize this difference in the total aggregate of metadiscourse used by one lecturer and by the other might have its roots in two possible factors: the fact that they use

\footnotetext{
* Developed by the Max Planck Institute for Psycholinguistics. Open source. Available for free at: https://tla.mpi.nl/tools/tlatools/elan/
} 
different languages, or the fact that they are different types of lecturers. Dudley-Evans(1994) identifies three types of lecturers: reading style lecturers, who simply read through their notes; conversational style lecturers, who rely on their notes and look at them for guidance but do not read through them; and rhetorical style lecturers, who do not usually employ notes and are seen more as performers. Following Dudley-Evans' categories and looking at our datasets, the African American lecturer would be considered a conversational style lecturer and the Human Resources lecturer would be rhetorical style.

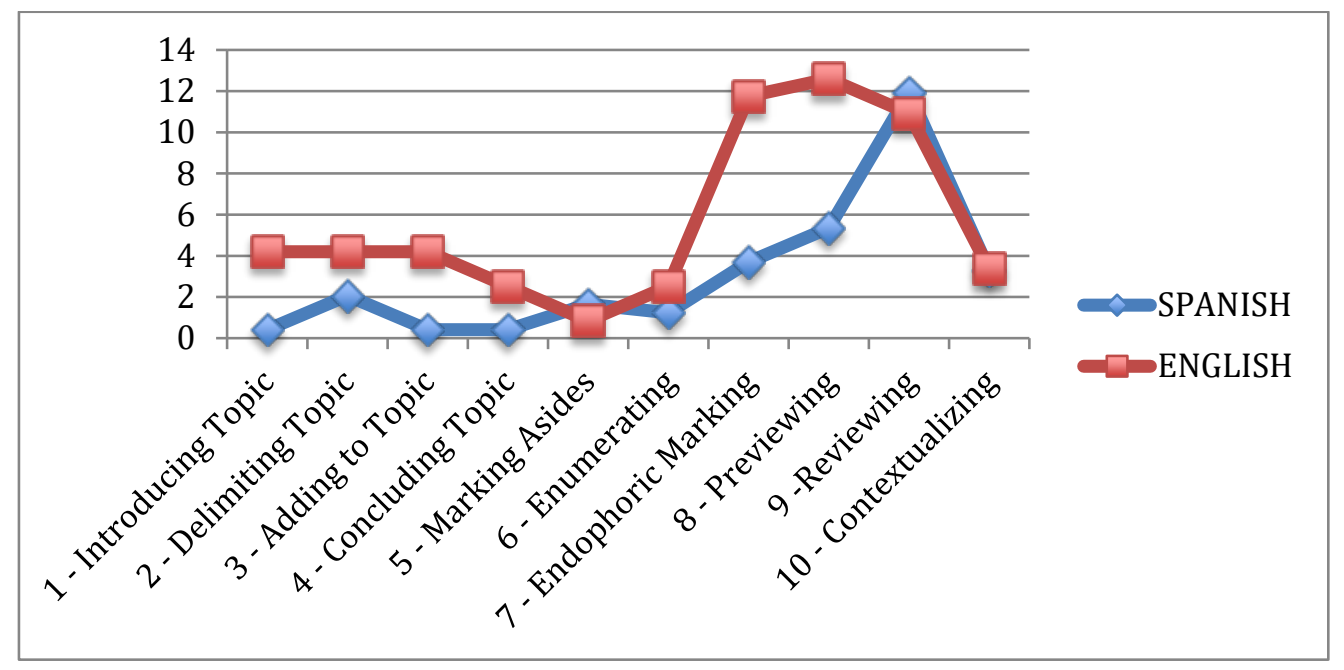

Figure 1: Number of organizational metadiscourse fragments every 10.000 words

The fact that conversational style lecturers rely on notes more than rhetorical style lecturers could imply a higher amount of connections among different parts of the discourse, as these are constantly at hand for the lecturer through their notes. Figure 1 shows more extensively the types and amounts of organizational metadiscourse used in both datasets.

As can be seen on Figure 1, there is a fairly similar amount of metadiscourse when used to mark asides, and enumerate as well as when reviewing material and contextualizing the lecture. There is, however, a slight difference in the amount of metadiscourse employed to talk about topics (categories 1 to 4); the number of instances of topic management metadiscourse use is higher in English. Again, it is our understanding that this variation, although not of much significance, could be related to the idea that topics might be more structured in the notes of the conversational style lecturer than in the case of the Spanish lecturer, where topics and ideas seem to blend one into the other. Nevertheless, the most notable contrast between the amount of metadiscourse used in one dataset and in the other has to do with endophoric marking and with previewing, whose utilization is clearly higher in English. Ädel (2010) refers to endophoric marking as those references to elements outside the discourse such as slides, books, or any other material accessible to the students. We believe that the use of endophoric marking is clearly class-dependent, and therefore, their use hinges on whether the lecturer employs such materials or not. In spite of that, the higher use of previewing in English is indeed relevant. Even though our dataset is not wide enough to reach any definite conclusions on the matter, we estimate that this difference could also be related to the lecturing styles and, as in the case of topic management, conversational style lecturers, who go back to their notes from time to time, may have a clearer structure of what is coming next and so they introduce this information to the students. 


\subsection{Multimodal Metadiscourse}

When conducting a Multimodal Discourse Analysis on the previewing and reviewing sections, the first differences in both datasets appeared at the linguistic level. We encountered a clear difference in the use of adverbial clauses when previewing and reviewing instances were specified, i.e. when lecturers tried to place in time the moment they were referring to. Examples 1 to 4 show examples of previewing and reviewing fragments in English while examples 5 to 8 show how this type of metadiscourse was specified in Spanish.

1. And we'll see how that control is manifested beyond the Klan and Birth of a Nation on Wednesday's lecture.

2. I'll clean that up a bit on Monday.

3. Now I ended last week's lecture talking about the founding of the NAACP, 1909.

4. And I've been talking about this the last couple of weeks.

5. Cuanto...mirad, es que, bueno, ahora lo veremos cuando lleguemos a cultura. (How much... look, the thing is, well, we'll see it when we get to culture).

6. (...) eso lo veremos ahora un poquito cuando lleguemos a informática, vale. (... we'll see that a little bit when we get to computing, ok).

7. Creo que un día os comenté esto del Trivers. (I think I told you about Trivers one day).

8. (...) todo eso, ¿vale?, que hemos hablado algunas veces, vale. (... all of that, ok?, that we've talked about sometimes, ok).

We observe that the use of adverbial clauses to state the moment the lecturers are referring to is much more specific in the case of the English lecture than it is in Spanish. This indicates that these references as well as the structure of the course might be clearer in the American lecture, while the Spanish use of adverbials is characterized by being more imprecise. This may as well have to do with the distinction between lecturers. Conversational style lecturers seem to be more restricted by the use of notes and clearly follow a prearranged structure.

When it comes to the non-linguistic use of metadiscourse, we came across a series of co-occurrences that could be observed in both sets of lectures. We identified a series of instances where organizational metadiscourse was used as appositions that were consistent both in English and in Spanish; in other words, the lecturer would interrupt the main sentence or the main discourse structure to preview or review information and then continue. In these cases, lecturers would normally use a parenthetical intonation -see, for instance Lelandais and Ferré (2014)-, i.e. they would decrease syllabic duration (speed up their speech pace) and decrease loudness; these appositions might also be preceded and followed by short pauses. Examples 9 and 10 (see Figure 2 and 3 for a snapshot from ELAN for each of them) illustrate how the waveforms are visually narrower when employing these types of metadiscourse.

9. Assisting this, or abetting this process even more, are the individuals, I mentioned before, labor agents.

10. Esto, claro, ¿cómo se crea esto? Pues ahora vamos a ver. Una es creando... (This, of course, how is this created? We'll see that now. One way is by creating...).

Similarly, we encountered further co-occurrences in both datasets when lecturers occasionally employ deictic gestures to point to the moment they are referring to in their previewing and reviewing uses of metadiscourse. 


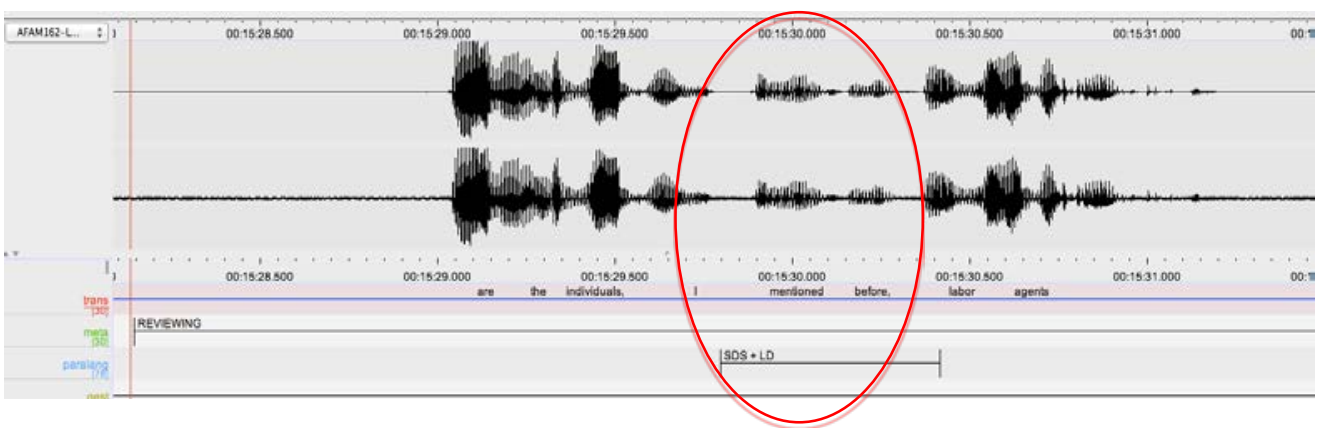

Figure 2: Parenthetical intonation in English, Example 9

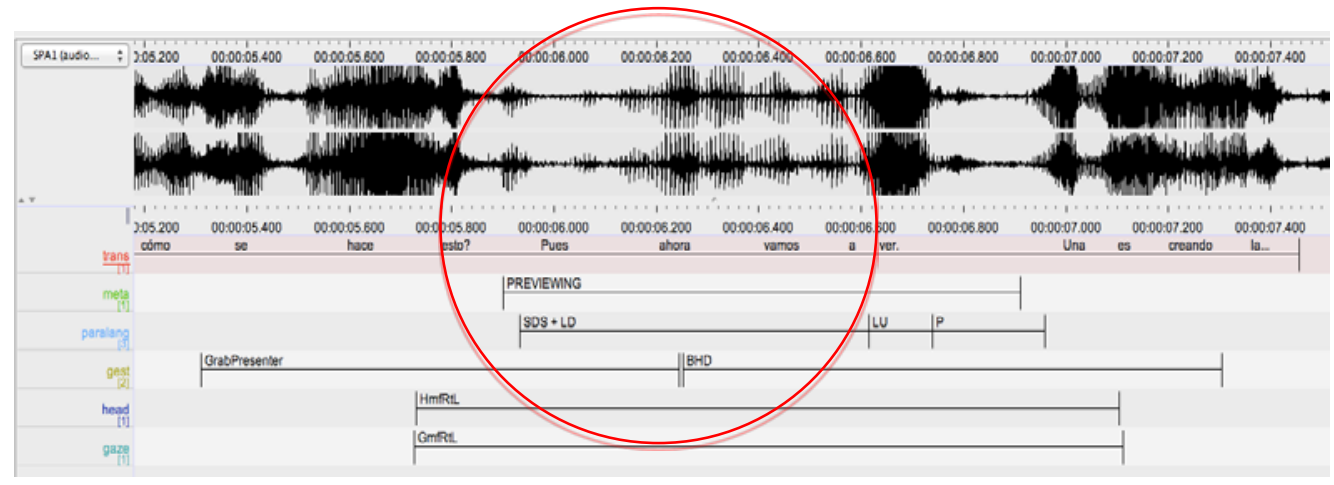

Figure 3: Parenthetical intonation in Spanish, Example 10

In this sense, example 11 is a fragment of previewing in one of the American lectures. Apart from using a parenthetical intonation as in the case of examples 9 and 10, the lecturer also accompanies this instance with a deictic gesture; when he specifies the moment they will be dealing with the migration of African Americans, he performs a gesture with both hands as to pointing to the future and intensifies the idea of "in a couple of weeks".

11. However, and we'll get to it in a couple of weeks, the migration of African Americans in the 1940s and early fifties (...).
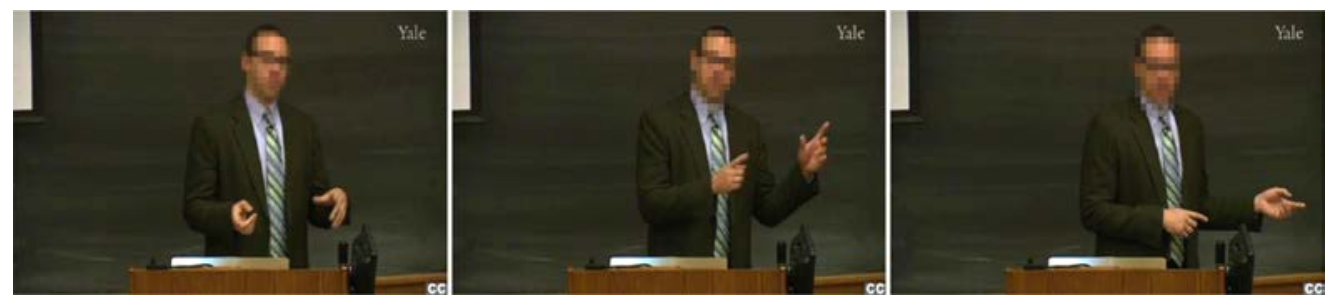

Figure 4: Gesturing in English, Example 11

Example 12 shows a rather homogeneous case in Spanish. The Human Resources lecturer interrupts the main sentence to include a previewing instance. As we mentioned before, the referent from the adverbial clause in Spanish is vaguer than it is in English but it still occurs together with another deictic gesture that, even though not as clearly as in example 11, also seems to point to a moment in the future. 
12. Si tú vas a una empresa, como veremos ahora con la cultura, la gente de administración dice... (If you go to a company, as we will see now with the culture, the people in administration say...).

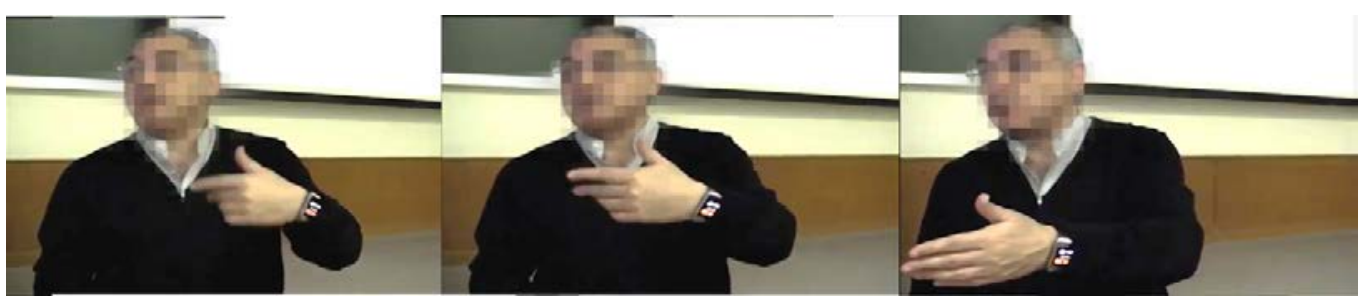

Figure 5: Gesturing in Spanish, Example 12

In both cases, the deictic gesture is used to accompany the previewing fragment of metadiscourse. It is not common, however, for this kind of fragments to occur with deictic gestures, but most of the times they are in fact attended by some sort of gesture that helps emphasize the connection of information within the discourse.

\section{Conclusion}

This paper has provided us with a deeper insight into the use of metadiscourse to organize academic lectures in English and in Spanish. The use of a multimodal approach allows us to examine communication beyond words so that we can discern the role played by other modes when conveying meaning. Our research was limited by the amount of lectures in our datasets and further research would be needed in order to make any generalizations. Nevertheless, our results point towards a difference in the amount of organizational metadiscourse used by the lecturers probably depending on the type of lecturer (conversational or rhetorical styles). Moreover, similarities in the use of paralinguistic and kinesic elements in the conveyance of previewing and reviewing have been spotted. Our final thoughts for this paper relate to the possible pedagogical implications of such results in EMI training where nonverbal aspects have traditionally been neglected.

\section{Acknowledgements}

Edgar Bernad-Mechó's contribution to this paper has been possible thanks to a scholarship granted by Universitat Jaume I (Ref: PREDOC/2013/49) and (Ref: E-2016-12). This article is also encompassed within a larger research project funded by Universitat Jaume I (Ref: P1·1B2015-72).

We would like to thank Open Yale Courses and Prof. Holloway as well as Prof. Grandío from Universitat Jaume I whose lectures made this study possible. 


\section{References}

Ädel, A. (2006). Metadiscourse in L1 and L2 English. Amsterdam \& Philadelphia: John Benjamins.

Ädel, A. (2010). Just to give you kind of a map of where we are going: A Taxonomy of Metadiscourse in Spoken and Written Academic English. Nordic Journal of English Studies, 9(2), 6997.

Crawford-Camiciottoli, B. (2007). The Language of Business Studies Lectures. A corpus-assisted analysis. Amsterdam \& Philadelphia: John Benjamins.

Crismore, A., Markkanen, R., \& Steffensen, M. (1993). Metadiscourse in persuasive writing: a study of texts written by American and Finnish university students. Written Communication, 10, 39-71.

Csomay, E. (2007). Variation in academic lectures: Interactivity and level of instruction. In R. S. Reppen, M. Fitmaurice, \& D. Biber (Eds.), Using corpora to explore linguistic variation (pp. 205-224). Amsterdam: John Benjamins.

Deroey, K. L. B., \& Taverniers, M. (2011). A corpus-based study of lecture functions. Moderna Språk, 105(2), 1-22.

Dudley-Evans, T. (1994). Variations in the discourse patterns favoured by different disciplines and their pedagogical implications. In J. Flowerdew (Ed.), Academic listening: research perspectives. (pp. 146-158). Cambridge: Cambridge University Press.

Fortanet-Gómez, I., \& Ruiz-Madrid, M. N. (2014). Multimodality for comprehensive communication in the classroom: questions in guest lectures. Ibérica, 28, 203-224.

Fortanet-Gómez, I., \& Ruiz-Madrid, M. N. (2015). Multimodal humour in plenary lectures in English and in Spanish. In B. Crawford-Camiciottoli \& I. Fortanet-Gómez (Eds.), Multimodal Analysis in Academic Settings: From Research to Teaching (pp. 39-60). New York: Routledge.

Halliday, M. A. K. (1973). Explorations in the Functions of Language. New York: Elsevier NorthHolland, Inc.

Hyland, K. (2005). Metadiscourse: Exploring interaction in writing. London, England: Continuum.

Hyland, K., \& Tse, P. (2004). Metadiscourse in academic writing: a reappraisal. Applied Linguistics, 6(2), 156-177.

Jakobson, R. (1960). Closing Statement: Linguistics and Poetics. In T. A. Sebeok (Ed.), Style in language (pp. 350-377). Cambridge, Mass: M.I.T. Press.

Lelandais, M., \& Ferré, G. (2014). Multimodal Analysis of Parentheticals in Conversational Speech. Multimodal Communication, 3(2), 197-217.

Pérez-Llantada, C., \& Ferguson, G. (2006). English as a glocalization phenomenon: Observations from a linguistic microcosm. (C. Pérez-Llantada \& G. Ferguson, Eds.). València: Universitat de València.

Prior, P. (2009). From speech genres to mediated multimodal genre systems: Bakhtin, Voloshinov, and the question of writing. In C. Bazerman, I. Bonini, \& D. Figueiredo (Eds.), Perspectives on Writing (pp. 17-34). Fort Collins, Colorado: The WAC Clearinghouse and Parlor Press.

Querol-Julián, M. (2010). Multimodality in discussion sessions: corpus compilation and pedagogical use. Language Value Journal, 2(1), 1-26.

Querol-Julián, M. (2011). Evaluation in discussion sessions of conference paper presentations: A multimodal approach. Saarbrücken: LAP Lambert Academic Publishing.

Querol-Julián, M., \& Fortanet-Gómez, I. (2012). Multimodal evaluation in academic discussion sessions: How do presenters act and react? English for Specific Purposes, 31, 271-283.

Ruiz-Madrid, M. N., \& Fortanet-Gómez, I. (2015). Contrastive Multimodal Analysis: Conference Plenary Lectures in English and in Spanish. In B. Crawford-Camiciottoli \& I. Fortanet-Gómez (Eds.), Multimodal Analysis in Academic Settings: From Research to Teaching (pp. 39-60). New York: Routledge. 
Toumi, N. (2009). A Model for the Investigation of Reflexive Metadiscourse in Research Articles. Language Studies Working Papers, 1, 64-73.

Vande Kopple, W. J. (1985). Some Exploratory Discourse on Metadiscourse. College Composition and Communication, 36(1), 82-93.

Vande Kopple, W. J. (2012). The importance of studying metadiscourse. Applied Research in English, 1(2), 37-44. 